\title{
COPD GUIDELINES: OLD GOLD VERSUS NEW GOLD
}

\author{
HAM NAZMUL AHASAN ${ }^{1}$, HOMAYRA TAHSEEN HOSSAIN ${ }^{2}$
}

\begin{abstract}
:
Chronic Obstructive Pulmonary Disease (COPD) is a major cause of chronic morbidity and mortality throughout the world. The Global Initiative for Chronic Obstructive Lung Disease (GOLD) is an international committee of experts who periodically update the knowledge on the diagnosis and management of COPD since 2001. This year 2017, the GOLD initiative published the 5-year update on the diagnosis and management of COPD.This review article mainly highlights the differences between old GOLD versus new GOLD guideline. Compared to the previous version, this documents has been an extensively revised: the definition has been simplified, highlighting the importance of respiratory symptoms, and disease development is further discussed, including new insights on lung development. Spirometry is no longer included in the $A B C D$ tool, which is now centered exclusively on respiratory symptoms and history of exacerbation. Subsequently, pharmacologic treatment has been shifted towards a more personalized approach. For the first time, GOLD proposes escalation strategies. Preference is given to LABA/LAMA (long-acting beta-agonist/long-acting muscarinic antagonists) combinations over LABA/ICS (long-acting beta-agonist/inhaled corticosteroid) combinations as a mainstay of treatment.
\end{abstract}

Keywords: Chronic obstructive pulmonary disease, GOLD guidelines, spirometry

Received: 09 November 2017

Accepted: 28 November 2017

DOI: http://dx.doi.org/10.3329/bjmed.v29i1.35405

\section{Introduction:}

Chronic Obstructive Pulmonary Disease (COPD) is a major cause of chronic morbidity and mortality throughout the world, comprising the fourth leading cause of death in the world. ${ }^{1}$ The Global Initiative for ChronicObstructive Lung Disease (GOLD) is an international committee of experts who periodically update the knowledge on the diagnosis and management of chronic obstructive pulmonary disease (COPD), based on an extensive scientific discussion and published evidence in the literature ${ }^{2}$

Since 2001 the document has been published every year reporting recommendations to be shared and implemented in different countries. This year 2017, the GOLD initiative published the 5-year update on the diagnosis and management of COPD with modified recommendations for the diagnosis, management and prevention of COPD.

\section{Redefining COPD:}

GOLD's definition of COPD was changed in its 2017 Report: "COPD is a common, preventable, and treatable disease that is characterized by persistent respiratory symptoms and airflow limitations that are due to airway and/or alveolar abnormalities usually caused by significant exposure to noxious particles or gases."

Compared to the previous definition, it introduces the concept of persistent symptoms, while discarding the putative pathogenic mechanism (i.e., enhanced inflammatory response); exacerbation, progression, and comorbidities are similarly not included in the revised definition of the disease.

GOLD 2017 recognizes that chronic respiratory symptoms (chronic dyspnea, cough and sputum production) may be present in the absence of abnormal spirometry, may be associated with structural lung alteration, and may precede the development of airflow limitation.$^{3}$

\section{Disease development \& Progression:}

Worldwide, the most commonly encountered risk factor for COPD is tobacco smoking. But, nonsmokers may also develop COPD. COPD is the result of a

1. Professor of Medicine, Popular Medical College Hospital, Dhaka

2. Associate Professor, Medicine, Popular Medical College Hospital, Dhaka

Address of correspondence: Professor HAM NazmulAhasan, Professor of Medicine, Popular Medical College Hospital, Dhaka. E-mail: ahasanhamn@yahoo.com

Bangladesh J Medicine 2018; 29 : 31-35 
complex interplay of long-term cumulative exposure to noxious gases and particles, combined with a variety of host factors including genetics, airway hyperresponsiveness and poor lung growth during childhood. ${ }^{4-6}$

Often, the prevalence of COPD is directly related to the prevalence of tobacco smoking, although in many countries outdoor, occupational and indoor air pollution (resulting from the burning of wood and other biomass fuels) are major COPD risk factors. ${ }^{7,8}$

Changes to COPD initial assessment \& severity:

GOLD continues to refine its ABCD grading system, introduced in 2011, to determine the severity of COPD. The primary criterion for diagnosis is unchanged: postbronchodilator forced expiratory volume in 1 second (FEV1)/forced vital capacity (FVC) less than 0.70 . Spirometry remains important to confirm the diagnosis in those with classic symptoms of dyspnea, chronic cough, and/or sputum production with a history of exposure to noxious particles or gases.

The GOLD assessment system previously incorporated spirometry and included an "ABCD" system such that patients in group A are least severe. Spirometry has been progressively deemphasized in favor of symptom-based classification and the 2017 Report, for the first time, dissociates spirometric findings from severity classification. So, airflow limitation (obstruction on spirometry) is not a component of the ABCD severity system in 2017 guideline, because airflow limitation correlates less well with functional limitation and quality of life than do patient reported symptoms and history of COPD exacerbations.

The new system uses symptom severity and exacerbation risk to classify COPD. Two specific standardized COPD symptom measurement tools, The Modified British Medical Research Council (mMRC) questionnaire and COPD Assessment Test (CAT), are reported by GOLD as the most widely used. ${ }^{9,10}$

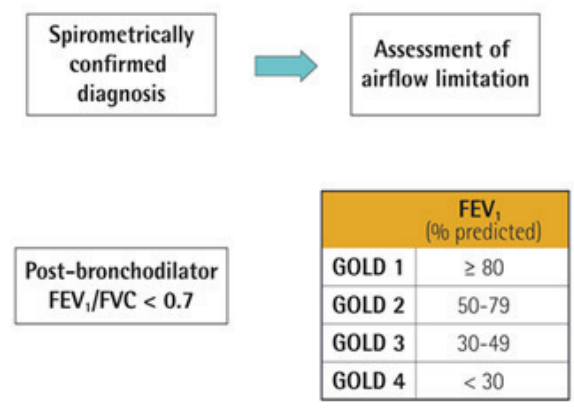

Figure 1: The refined $A B C D$ assessment tool
Table-I

Modified MRC dyspnea scale

\begin{tabular}{|c|c|}
\hline $\begin{array}{l}\text { PLEASE TICK IN THE BOX THAT APPLLES TO YOU } \\
\text { (ONE BOX ONLY) (Grades O-4) }\end{array}$ & \\
\hline mMRC Grade 0. I only get breathless with strenvous exercise. & ] \\
\hline mMRC Grade 1 . I get short of breath when hurning on the level or walking up a slight hill. & ] \\
\hline $\begin{array}{l}\text { mMRC Grade 2. I walk slower than people of the same age on the level beccusse of breathlessness or I have to stop for } \\
\text { breath when waking on my own pace on the level. }\end{array}$ & ] \\
\hline mMRC Grade 3 . I stop for breath after walking about 100 meters or after a few minuts on the level. & ] \\
\hline mMRC Grade 4 . I am too breathless to levve the house or I am breathless when dressing or undressing. & ] \\
\hline
\end{tabular}

Table-II

CAT (COPD Assessment Test) Assessment:

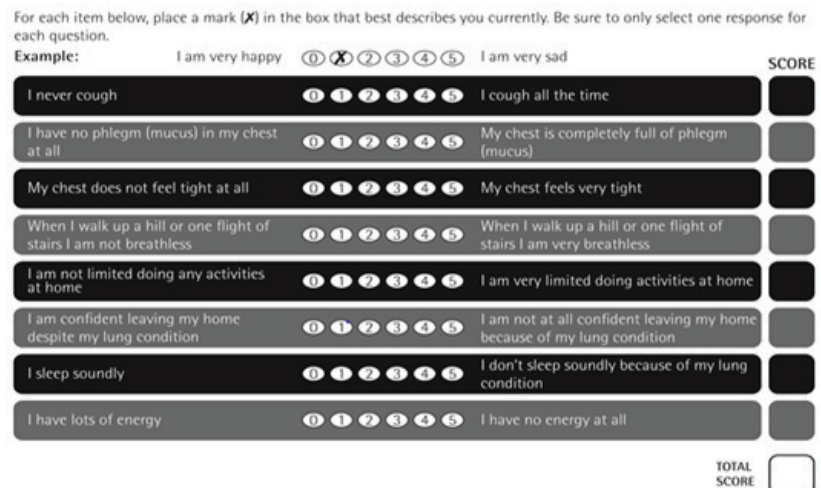

In the refined assessment scheme,

- Patients should undergo spirometry to determine the severity of airflow limitation (i.e., spirometric grade).

- They should then undergo assessment of either dyspnea using mMRC or symptoms using CAT.

- Finally, their history of exacerbations (including prior hospitalizations) should be recorded.

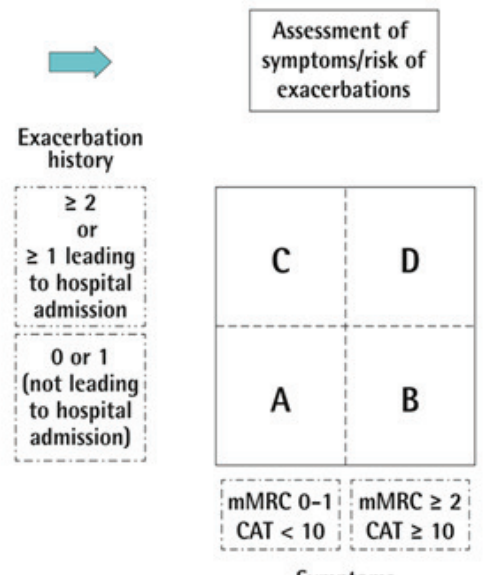

Symptoms 
Thus, symptom severity and exacerbation risk is divided into four quadrants:

- GOLD group A: Low symptom severity, low exacerbation risk.

- GOLD group B: High symptom severity, low exacerbation risk.

- GOLD group C: Low symptom severity, high exacerbation risk.

- GOLD group D: High symptom severity, high exacerbation risk.

Example: If we consider two patients - both patients with FEV $1<30 \%$ of predicted, CAT scores of 16 and one with no exacerbations in the past year and the other with four exacerbations in the past year. Both would have been labeled GOLD D in the prior classification scheme. However, with the new proposed scheme, the subject with 4 exacerbations in the past year would be labelled GOLD grade 4, group $\mathrm{D}$; the other subject with no exacerbations would be labeled GOLD Grade 4, group B.

This classification scheme may facilitate consideration of individual therapies and also help guide escalation and de-escalation therapeutic strategies for a specific patient.

Changes to prevention and management of stable COPD:

Smoking cessation remains important in the prevention of COPD. The 2017 Report reflects the Preventive Services guidelines for smoking cessation: Offer nicotine replacement, cessation counseling, and pharmacotherapy (varenicline, bupropion or nortriptyline).

- Vaccination:Influenza vaccination can reduce serious illness (such as lower respiratory tract infections requiring hospitalization $)^{11}$ and death in COPD patients.12-14 Pneumococcal vaccinations, PCV13 and PPSV23, are recommended for all patients e" 65 years of age. The PPSV23 is also recommended for younger COPD patients with significant comorbid conditions including chronic heart or lung disease. ${ }^{15}$

- Pulmonary rehabilitation improves symptoms, quality of life, and physical and emotional participation in everyday activities. The patient with COPD is asked to play an active role in the whole management of the disease, through self- management, participation in rehabilitation programs, and discussion over end of life and prolonged care.

- Evaluation of the inhaler technique is now recommended. According to recent data on inhaler technique errors, it seems that only $6 \%$ of the patients have an optimal skill and adherence with inhalers ${ }^{16}$. Thus, it is necessary that clinicians recognize the different devices and techniques, and suggest the most appropriate for each individual patient. ${ }^{17}$

- Oxygen therapy: The 2017 GOLD guidelines generally advise against the routine practice of prescribing supplemental oxygen to stable COPD patients without severe resting hypoxemia.

The guidelines do suggest thatindividual patient factors may be considered when evaluating a patient's need for supplemental oxygen. COPD patients with severe resting hypoxemia (oxygen saturation d" $88 \%$ and certain other patients with COPD) should all receive supplemental oxygen to be worn continuously.

\section{The ABCDs of stable COPD Treatment in 2017 GOLD Guidelines:}

There were several changes to the pharmacologic treatment algorithm in 2017 guideline. For the first time, GOLD proposes escalation strategies. Preference is given to LABA/LAMA (long-acting betaagonist/long-acting muscarinic antagonists) combinations over LABA/ICS (long-acting betaagonist/inhaled corticosteroid) combinations as a mainstay of treatment.

The rationale for this change is that LABA/LAMAs give greater bronchodilation compared with LABA/ ICS, and one study showed a decreased rate of exacerbations compared to LABA/ICS in patients with a history of exacerbations. ${ }^{18,19}$ In addition, patients with COPD who receive ICS appear to have a higher risk of developing pneumonia.

Antibiotics: More recent studies have shown that regular use of macrolide antibiotics may reduce exacerbation rate. ${ }^{20,21}$

The 2017 GOLD guidelines go further in advising physicians exactly what class of medication to use, in which COPD patients according to where they fall in the $A B C D$ grading scheme: 

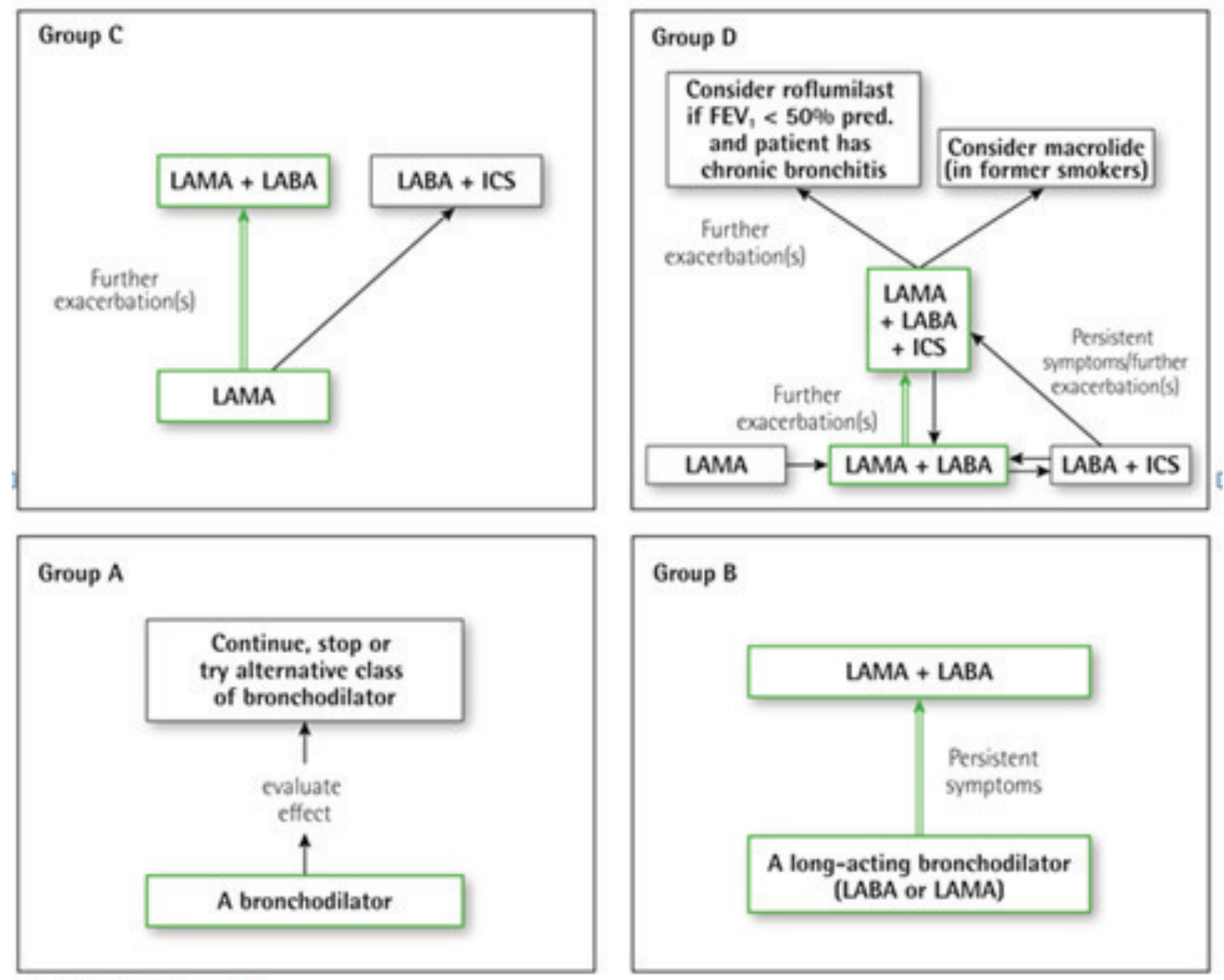

Aefemed treatment - $=$

Figure 2: Pharmacological treatment algorithms by GOLD Grade (highlighted boxes and arrows indicate preferred treatment pathways)

\section{Management of Exacerbations:}

- An exacerbation of COPD is defined as an acute worsening of respiratory symptoms that results in additional therapy.

- Short-acting inhaled beta2-agonists, with or without short-acting anticholinergics, are recommended as the initial bronchodilators to treat an acute exacerbation.

- Maintenance therapy with long-acting bronchodilators should be initiated as soon as possible before hospital discharge.

- Systemic corticosteroids can improve lung function (FEV1), oxygenation and shorten recovery time and hospitalization duration. Duration of therapy should not be more than 5-7 days.

- Antibiotics, when indicated, can shorten recovery time, reduce the risk of early relapse, treatment failure, and hospitalization duration. Duration of therapy should be 5-7 days.
- Methylxanthines are not recommended due to increased side effect profiles.

- Non-invasive mechanical ventilation should be the first mode of ventilation used in COPD patients with acute respiratory failure who have no absolute contraindication because it improves gas exchange, reduces work of breathing and the need for intubation, decreases hospitalization duration and improves survival.

\section{Comorbidities:}

Finally, the 2017 GOLD document devotes new insights to comorbidities in its last chapter. COPD is known to be associated with other concomitant conditions, including cardiovascular and muscularskeletal diseases, osteoporosis, mood disorders, and cancer, evoking multimorbidity as the most likely clinical figure in these patients ${ }^{22}$. Accordingly, the importance of the active search, diagnosis, and treatment of any comorbidity associated to COPD is now recommended. 


\section{Conclusion:}

The GOLD 2017 document reports several new insights into the diagnosis and the management of the patients with COPD. This seems a step toward achieving a comprehensive, personalized and patientcentered approach.

\section{References:}

1. Lozano R, Naghavi M, Foreman K, et al. Global and regional mortality from 235 causes of death for 20 age groups in 1990 and 2010: a systematic analysis for the Global Burden of Disease Study 2010. Lancet 2012; 380(9859): 2095-128.

2. Vogelmeier CF, Criner GJ, Martinez FJ, Anzueto A, Barnes PJ, Bourbeau J, et al. Global Strategy for the Diagnosis, Management, and Prevention of Chronic Obstructive Lung Disease 2017 Report: GOLD Executive Summary. EurRespir J. 2017;49(3).

3. Global Initiative for Chronic Obstructive Lung Disease (GOLD). Global Strategy for the Diagnosis, Management and Prevention of COPD. Available from: http://www.goldcopd.org. (Accessed Apr 2017).

4. Lange $\mathrm{P}$, Celli B, Agusti A, et al. Lung-Function Trajectories Leading to Chronic Obstructive Pulmonary Disease. N Engl J Med 2015; 373(2): 111-22.

5. Stern DA, Morgan WJ, Wright AL, Guerra S, Martinez FD. Poor airway function in early infancy and lung function by age 22 years: a non-selective longitudinal cohort study. Lancet 2007; 370(9589): 758-64

6. Tashkin DP, Altose MD, Bleecker ER, et al. The lung health study: airway responsiveness to inhaled methacholine in smokers with mild to moderate airflow limitation. The Lung Health Study Research Group. Am Rev Respir Dis 1992; 145(2 Pt 1): 30110 .

7. Eisner MD, Anthonisen N, Coultas D, et al. An official American Thoracic Society public policy statement: Novel risk factors and the global burden of chronic obstructive pulmonary disease. Am J RespirCrit Care Med 2010; 182(5): 693-718.

8. Salvi SS, Barnes PJ. Chronic obstructive pulmonary disease in non-smokers. Lancet 2009; 374(9691): 733-43.

9. Sundh J, Janson C, Lisspers K, Stallberg B, Montgomery S. The Dyspnoea, Obstruction, Smoking, Exacerbation (DOSE) index is predictive of mortality in COPD. Prim Care Respir J 2012; 21(3): 295-301.

10. Nishimura K, Izumi T, Tsukino M, Oga T. Dyspnea is a better predictor of 5-year survival than airway obstruction in patients with COPD. Chest 2002; 121(5): 1434-40.
11. Wongsurakiat $\mathrm{P}$, Maranetra KN, Wasi C, Kositanont U, Dejsomritrutai W, Charoenratanakul S. Acute respiratory illness in patients with COPD and the effectiveness of influenza vaccination: a randomized controlled study. Chest 2004; 125(6): 2011-20.

12. Poole PJ, Chacko E, Wood-Baker RW, Cates CJ. Influenza vaccine for patients with chronic obstructive pulmonary disease. Cochrane Database Syst Rev 2006; (1): CD002733.

13. Wongsurakiat P, Lertakyamanee J, Maranetra KN, Jongriratanakul S, Sangkaew S. Economic evaluation of influenza vaccination in Thai chronic obstructive pulmonary disease patients. J Med Assoc Thai 2003; 86(6): 497-508.

14. Nichol KL, Margolis KL, Wuorenma J, Von Sternberg T. The efficacy and cost effectiveness of vaccination against influenza among elderly persons living in the community. N Engl J Med 1994; 331(12): 77884 .

15. Tomczyk S, Bennett NM, Stoecker C, et al. Use of 13-valent pneumococcal conjugate vaccine and 23valent pneumococcal polysaccharide vaccine among adults aged $>/=65$ years: recommendations of the Advisory Committee on Immunization Practices (ACIP). MMWR Morb Mortal Wkly Rep 2014; 63(37): 822-5.

16. Sulaiman I, Cushen B, Greene G, Seheult J, Seow D, Rawat F, et al. Objective Assessment of Adherence to Inhalers by COPD Patients. Am J RespirCrit Care Med. 2016. doi:10.1164/rccm.201604-07330C.

17. Laube BL, Janssens HM, de Jongh FHC, Devadason SG, Dhand R, Diot P, et al. What the pulmonary specialist should know about the new inhalation therapies. EurRespir J. 2011;37(6):1308-31.

18. Cazzola M, Molimard M. The scientific rationale for combining long-acting beta2-agonists and muscarinic antagonists in COPD. Pulm Pharmacol Ther 2010; 23(4): 257-67.

19. Tashkin DP, Pearle J, Iezzoni D, Varghese ST. Formoterol and tiotropium compared with tiotropium alone for treatment of COPD. COPD 2009; 6(1): 1725.

20. Herath SC, Poole P. Prophylactic antibiotic therapy for chronic obstructive pulmonary disease (COPD). Cochrane Database Syst Rev 2013; (11): CD009764.

21. Ni W, Shao X, Cai X, et al. Prophylactic use of macrolide antibiotics for the prevention of chronic obstructive pulmonary disease exacerbation: a metaanalysis. PloS one 2015; 10(3): e0121257.

22. Multimorbidity: clinical assessment and management. NICE Guidance and guidelines. Available from: https://www.nice.org.uk/ guidance/ng56. (Accessed May 2017). 